\title{
Reduction of Mutual Coupling and Return Loss in Microstrip Array Antennas Using Concave Rectangular Patches
}

\author{
Shahram Mohanna, Ali Farahbakhsh, Saeed Tavakoli, and Nasser Ghassemi \\ Faculty of Electrical and Computer Engineering, The University of Sistan and Baluchestan, Zahedan 9816745563, Iran \\ Correspondence should be addressed to Shahram Mohanna, mohana@hamoon.usb.ac.ir
}

Received 1 September 2010; Revised 13 November 2010; Accepted 17 December 2010

Academic Editor: Samir Trabelsi

Copyright () 2010 Shahram Mohanna et al. This is an open access article distributed under the Creative Commons Attribution License, which permits unrestricted use, distribution, and reproduction in any medium, provided the original work is properly cited.

\begin{abstract}
An effective solution to reduce both the mutual coupling and return loss of a microstrip array antenna consisting of rectangular patches is proposed. The patch is made concave in both horizontal and vertical sides. Applying the proposed structure to a microstrip array antenna having two elements, the effects of patch concavity on the mutual coupling and return loss are simulated and studied. To obtain a concave rectangular patch array antenna having low amounts of mutual coupling and return loss, the patch length and width as well as the amounts of concavities are optimized using an enhanced genetic algorithm. To verify the simulation results, then, the optimal array antenna is fabricated. The simulation and experimental results confirm that the optimal concave rectangular array antenna has low amounts of mutual coupling and return loss.
\end{abstract}

\section{Introduction}

Because of its benefits, such as small size, simple manufacturing, flexibility, light weight, and low cost, the usage of microstrip array antennas is quickly increasing [1-4]. They are widely used in applications such as pattern beam forming, smart antennas, and electronic scanning radars $[5,6]$.

Mutual coupling and return loss are important factors which must be considered in the design of array antennas. When one array element radiates, a portion of its radiated power is absorbed by other elements and induces current on them. The mutual coupling effect leads to problems such as beam forming error, scanning error, and input power wastage [7-9]. Therefore, the effect of mutual coupling must be reduced in array antenna design. To do this, several methods such as changing feed position, feed structure, or patch shape have been reported [10-14].

Employing concave rectangular patches [15] instead of ordinary ones, an efficient solution to reduce mutual coupling in a linear array of microstrip antennas was proposed in [10]. The effectiveness of the proposed method was approved by the simulation results. In this paper, the microstrip array antennas with both ordinary and concave rectangular patches are fabricated and tested to verify the simulation results given in [10].

\section{Structure of Array Antenna}

The antenna structure includes two dielectric layers. The patches are placed on the upper conductive layer. The middle conductive layer is a feed layer, and the lower one is assumed to be an infinite ground plane. Using commercial microstrip boards data sheets, the relative permittivity, $\varepsilon_{r}$, of the substrate and its dissipation factor, $\tan \delta$, are equal to 2.2 and 0.0009 , respectively. Also, the thickness of dielectric layers, $D_{1}$ and $D_{2}$, is equal to $0.38 \mathrm{~mm}$. The side view of the antenna is depicted in Figure 1.

The patch dimensions are determined by the antenna resonant frequency $[1,2]$. In this paper, the antenna is designed for X-band applications and its resonant frequency is set to be $8.4 \mathrm{GHz}$. As a result, the length and width of the patches are given by $L=11.38 \mathrm{~mm}$ and $W=11.55 \mathrm{~mm}$, respectively. The patches are fed by proximity-coupled mechanism and $L$-shapeed feed lines, which are used to separate ports from each other to be fed by SMA connectors. The impedance of each feed line is $50 \Omega$. The intersection of feed line and patch, 


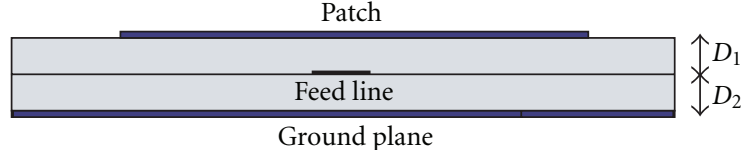

FIgURE 1: Structure of the antenna.

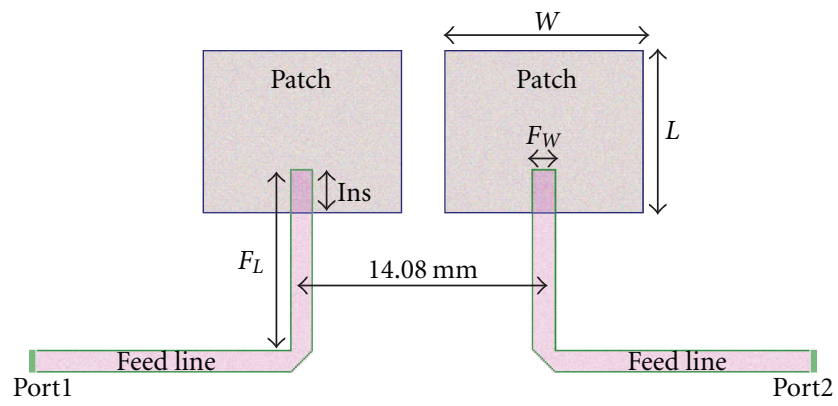

Figure 2: Structure of the array antenna.

ins, is $3.50 \mathrm{~mm}$. In this study, the array antenna includes two elements, which are placed horizontally on one substrate. The distance between the elements is $14.08 \mathrm{~mm}$. The array antenna structure and its dimensions are shown in Figure 2.

The array antenna is simulated by FEKO [16]. As can be seen from Figure 4, the amounts of reflection coefficient and mutual coupling of the above array antenna are far from ideal.

\section{Concave Array Antenna}

The array antenna with concave patches is shown in Figure 3. The circular concavity is used and its depths in patch width and length are shown by $h_{1}$ and $h_{2}$, respectively. The effect of patch concavity on antenna return loss and mutual coupling was studied in [10]. It was shown that the length concavity shifts the resonant frequency down. To compensate this effect and return the resonant frequency back to its initial value, the dimension of patch must be decreased. Therefore, the obtained patch is smaller than a rectangular patch at the same frequency. Obviously, when the patch dimensions are decreased, the distance between patches and, hence, the mutual coupling, will be increased. On the other hand, the width concavity shifts the resonant frequency up. Therefore, the electrical distance between patches and, consequently, the mutual coupling are increased.

A change in the amount of concavity in length or width results in an alteration in the resonant frequency of antenna. As a result, the patch impedance is distorted and must be corrected by changing the other antenna parameters, such as the patch width. Since it is very difficult to analyze this type of antenna, the design procedure can be accomplished by changing the antenna parameters using numerical optimization methods, such as genetic algorithms. As simulation of the antenna is a time-consuming procedure, an enhanced genetic algorithm [17], which is faster and more accurate than conventional genetic algorithms, is employed in this research work.

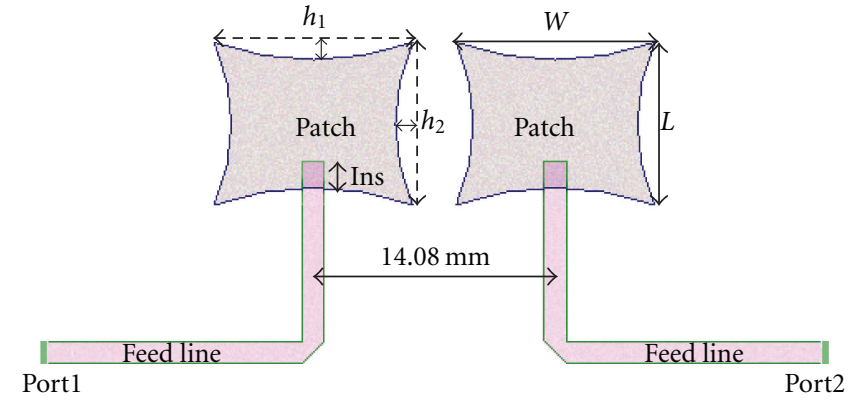

FIgURE 3: Array of concave antennas.

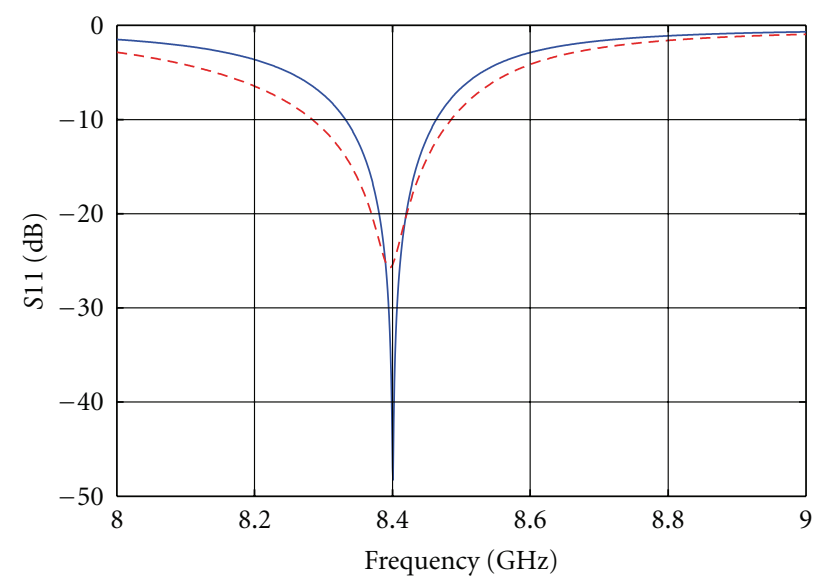

(a)

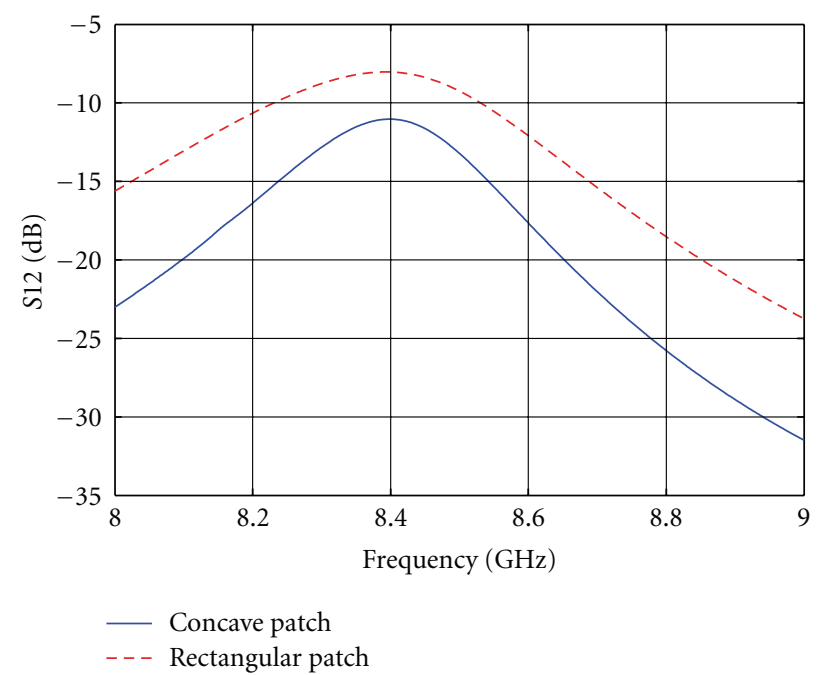

(b)

FIGURE 4: (a) Simulated reflection coefficient and (b) mutual coupling of the optimal concave patch and ordinary rectangular patch array antennas.

The optimization procedure aims to minimize the amounts of return loss and mutual coupling at a resonant frequency of $8.4 \mathrm{GHz}$. Optimization variables are dimensions of the patches, $W$ and $L$, the amount of patch and feed line intersection, ins, feed line width and length, $F_{W}$ and $F_{L}$, and amounts of patch concavity, $h_{1}$ and $h_{2}$, as shown in Figures 2 and 3 . 


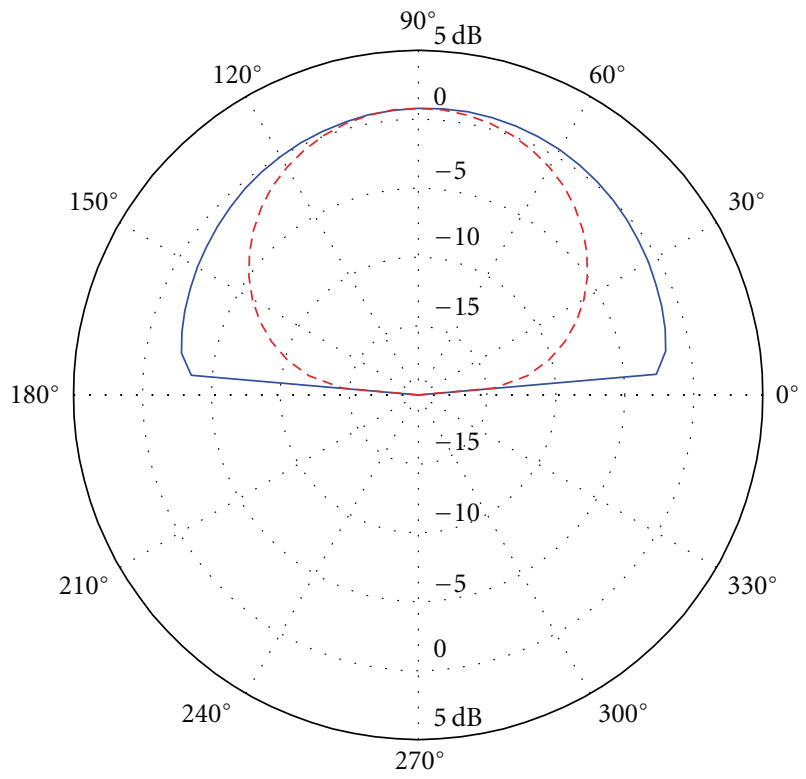

(a)

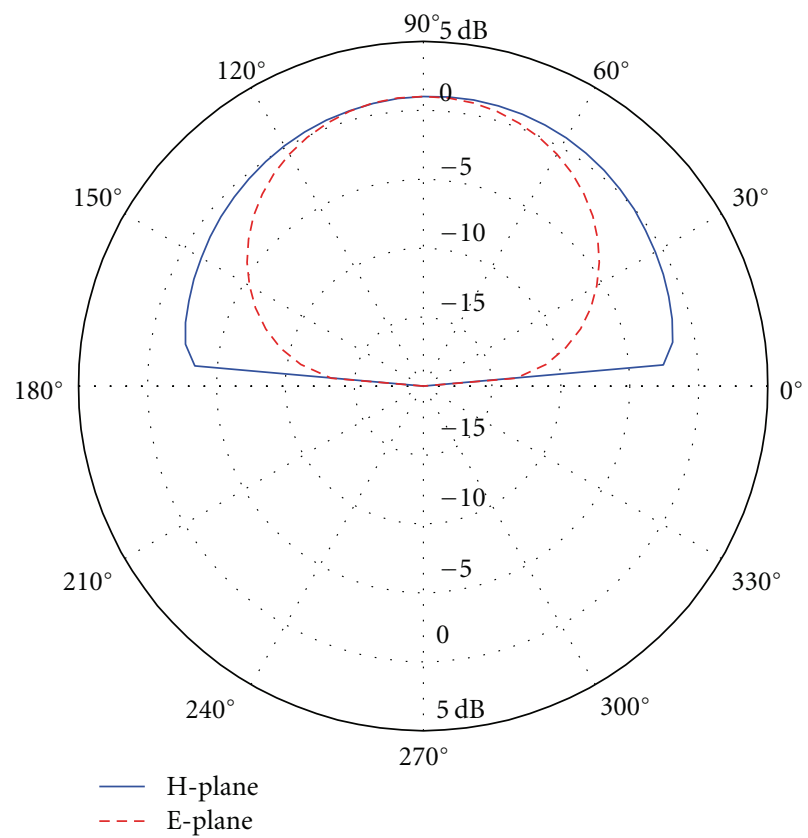

(b)

FIGURE 5: Simulated E-field radiation pattern for (a) ordinary rectangular patch and (b) concave patch array antennas.

The range of $W$ and $L$ is considered to be between 7 and $15 \mathrm{~mm}$. These parameters affect the input impedance and resonant frequency of the antenna, respectively. $F_{W}$, which affects the line impedance, varies from $0.7 \mathrm{~mm}$ to $1.5 \mathrm{~mm}$. Variation of $F_{L}$ is between 7 and $15 \mathrm{~mm} . F_{L}$ and $F_{W}$ are used for impedance matching of the patch and feed line.

In this study, a code was written in Matlab [18] based on the enhanced genetic algorithm. Then, the Matlab code was linked to FEKO to optimize the array antenna. Running optimization procedure, the optimal parameters are given by $W=10.076, L=11.496, F_{W}=1.11, F_{L}=10.45, h_{1}=0.56$,

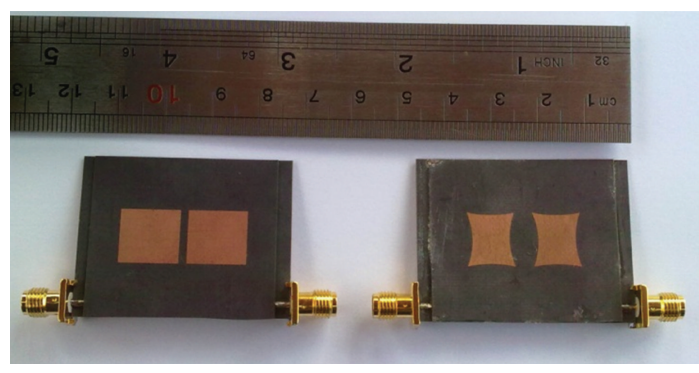

(a)

(b)

Figure 6: Fabricated (a) rectangular and (b) concave patch array antennas.

and $h_{2}=1.115$, all in $\mathrm{mm}$. The concave rectangular patch array antenna based on these optimal parameters is simulated using FEKO. In Figure 4, the reflection coefficient and mutual coupling of both the optimal concave patch and ordinary rectangular patch array antennas are compared.

It can be seen from Figure 4(a) that the reflection coefficient of the optimal concave array antenna in the resonant frequency is almost $-48 \mathrm{~dB}$, which is about $23 \mathrm{~dB}$ less than that of the ordinary rectangular array antenna. Moreover, Figure 4(b) shows that the amount of mutual coupling between the antenna elements is decreased by about $3 \mathrm{~dB}$. Overall, the proposed optimal concave array antenna has low amounts of mutual coupling and reflection coefficient.

Figure 5 shows the E-field radiation pattern of the rectangular patch and concave patch in E-plane and H-plane. The comparison of Figures 5(a) and 5(b) verifies that the concavity in the patches does not change the radiation pattern of the array antenna. Therefore, having the same antenna specifications, the return loss of the array antenna can be decreased employing concavity in the patches.

\section{Experimental Results}

To approve the simulations described in Sections 2 and 3, both the ordinary rectangular patch and optimal concave rectangular patch array antennas were fabricated and tested. In the microstrip board, the dimension of the ground plane for each antenna is $46 \times 35 \mathrm{~mm}$. Figure 6 shows the fabricated concave and rectangular array antennas. The measured reflection coefficient and mutual coupling of both antennas are illustrated in Figure 7.

It can be seen from Figure 7 that the mutual coupling and reflection coefficient of the concave rectangular patch array antenna are smaller than those of the ordinary rectangular patch array antenna. The comparison of the simulations (Figure 4) and the experimental results (Figure 7) verifies that creating concavity in the patches is an effective solution to reduce the mutual coupling and return loss in the microstrip array antennas. Because the fabricated antennas have finite ground planes, we already expected a difference between simulation and experimental results.

The normalized E-field radiation pattern of both antennas in $\mathrm{E}$ and $\mathrm{H}$ planes is measured and illustrated in Figure 8. In comparison with the simulations described in 


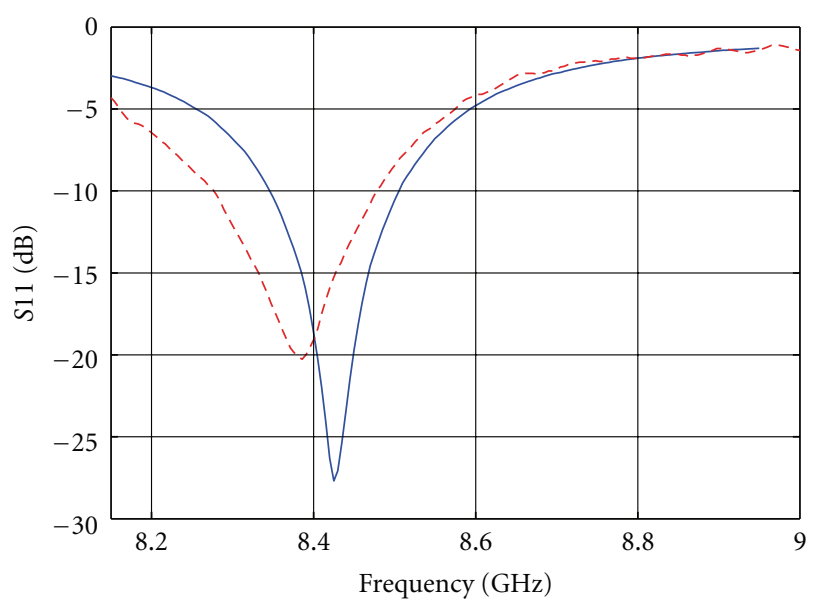

(a)

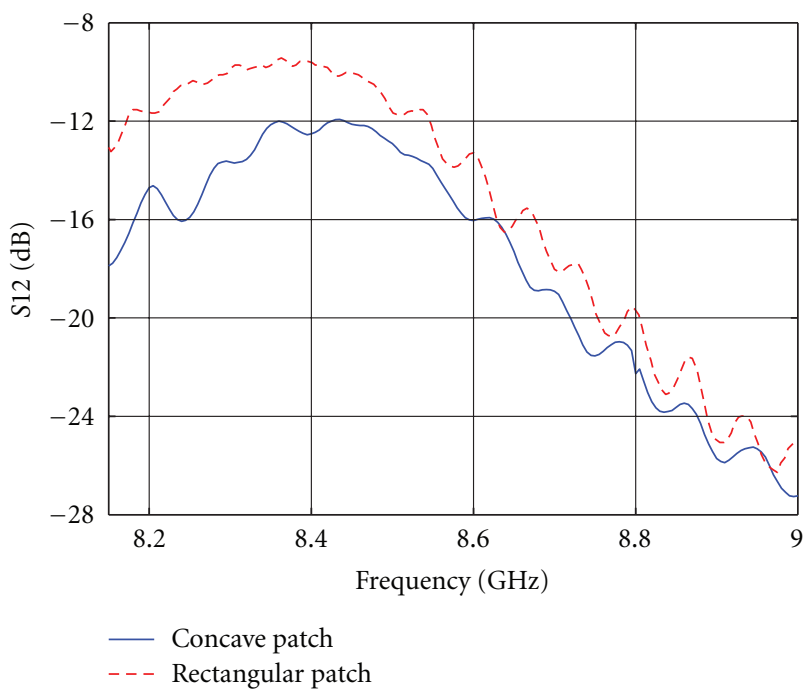

(b)

Figure 7: Measured reflection coefficient and mutual coupling of the optimal concave patch and ordinary rectangular patch array antennas.

Figure 5, the measured patterns show that the array antennas have back lobes, whilst such an effect is not seen in the simulations. Additionally, the concave array antenna has a wider pattern than the rectangular array antenna, because the size of the concave patch is smaller than that of the rectangular patch.

As described, some differences exist between the simulation and the measurement results. The main reason is that, in the simulations, the ground plane was assumed to be infinity, whereas in the fabricated antennas, the infinite ground plane cannot be implemented. In addition, due to differences that occurred in fabricating process, it is difficult to exactly match the physical parameters of the fabricated and simulated concave rectangular patch array antennas. Therefore, the simulated and measured resonant frequencies of the optimal concave rectangular patch array antenna are slightly different. Ignoring such small dissimilarities, a fairly good agreement between simulation and experimental

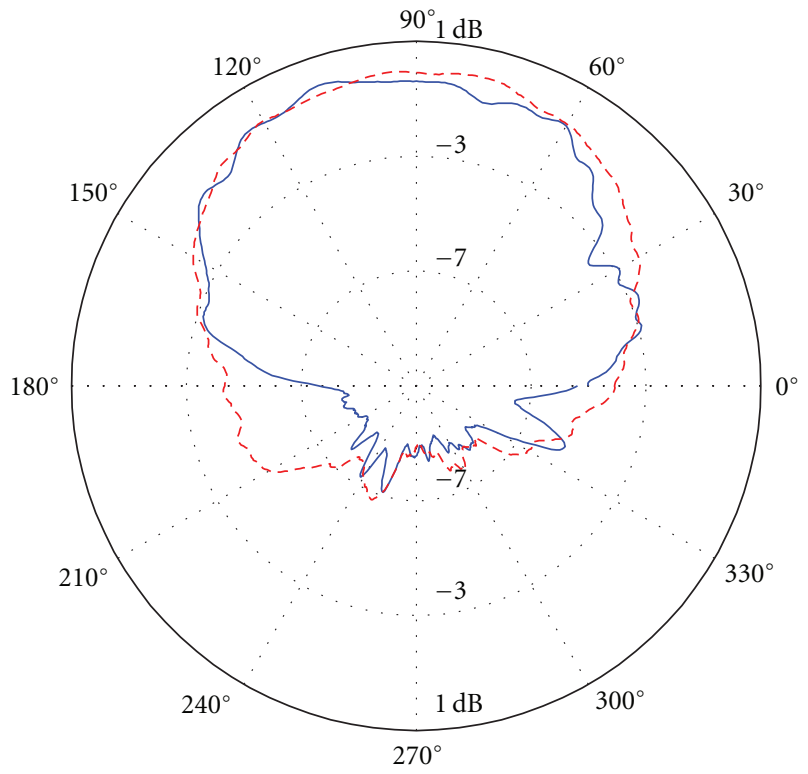

(a)

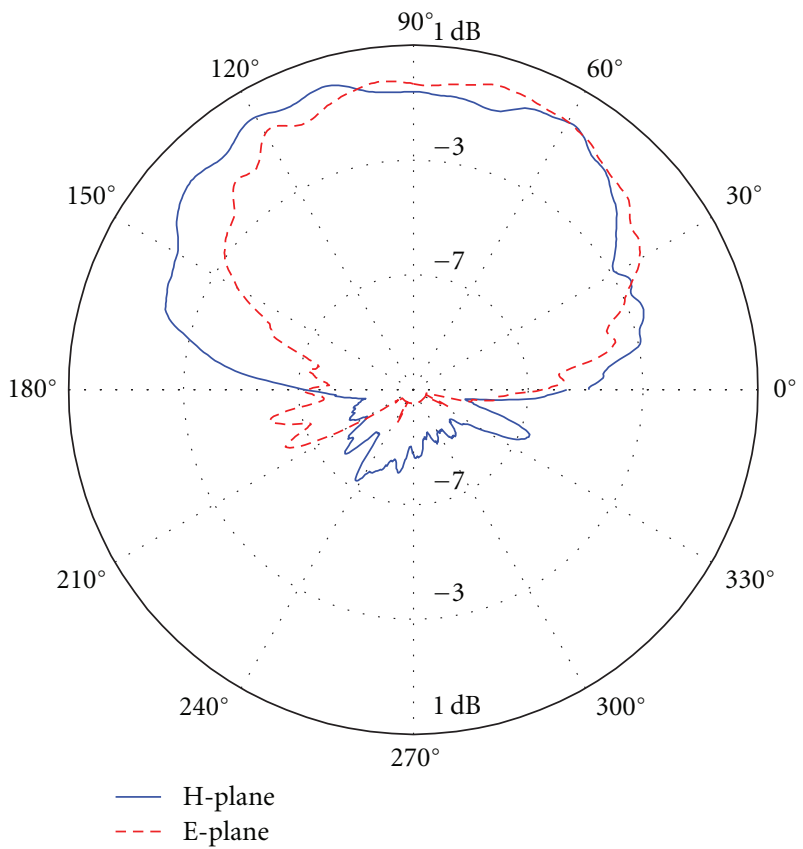

(b)

Figure 8: The measured normalized E-field radiation pattern for (a) ordinary rectangular patch and (b) concave patch array antennas.

results is presented. Overall, it can be concluded that the use of concave patches is an efficient solution to reduce the mutual coupling effect and reflection coefficient.

\section{Conclusions}

In this paper, an efficient solution to reduce mutual coupling and return loss in microstrip array antennas consisting of rectangular patches was proposed. The patch length and 
width as well as the amount of width and length concavities were optimized using an enhanced genetic algorithm. Then, the optimal concave array antenna was fabricated. The simulation and experimental results demonstrated that the optimal concave rectangular patch array antenna has low amounts of mutual coupling and return loss in comparison with the ordinary rectangular patch array antenna.

\section{References}

[1] C. A. Balanis, Modern Antenna Handbook, John Wiley \& Sons, New York, NY, USA, 2008.

[2] D. M. Pozar, "Microstrip antennas," Proceedings of the IEEE, vol. 80, no. 1, pp. 79-91, 1992.

[3] K. R. Carver and J. W. Mink, "Microstrip antenna technology," IEEE Transactions on Antennas and Propagation, vol. 29, no. 1, pp. 2-24, 1981.

[4] N. Ghassemi, J. Rashed-Mohassel, Sh. Mohanna, and Gh. Moradi, "A wideband aperture-coupled microstrip antenna for S and C bands," Microwave and Optical Technology Letters, vol. 51, no. 8, pp. 1807-1809, 2009.

[5] R. Osman, Microstrip array antenna for automobile radar system, M.S. thesis, University Technology Malaysia, 2006.

[6] N. Ghassemi and Sh. Mohanna, "Wideband microstrip array antenna using aperture coupled elements," in Proceedings of the Progress in Electromagnetic Research Symposium, Moscow, Russia, 2009.

[7] K. R. Dandekar, H. Ling, and G. Xu, "Effect of mutual coupling on direction finding in smart antenna applications," Electronics Letters, vol. 36, no. 22, pp. 1889-1891, 2000.

[8] R. Bhagavatula, R. W. Heath Jr., A. Forenza, N. J. Kirsch, and K. R. Dandekar, Impact of Mutual Coupling on Adaptive Switching between MIMO Transmission Strategies and Antenna Configurations, Springer Science and Business Media, 2008.

[9] S. Jarchi, J. Rashed-Mohassel, and M. H. Neshati, "Mutual coupling of rectangular DRA in a four element circular array," in Proceedings of the Progress in Electromagnetics Research Symposium, Beijing, China, 2007.

[10] A. Farahbaksh, Sh. Mohanna, and S. Tavakoli, "Reduction of mutual coupling in microstrip array antennas using concave rectangular patches," in Proceedings of the International Symposium on Antennas and Propagation, Bangkok, Thailand, 2009.

[11] A. Farahbakhsh, Sh. Mohanna, S. Tavakoli, and M. OukatiSadegh, "New patch configurations to reduce the mutual coupling in microstrip array antenna," in Proceedings of the Antennas and Propagation Conference (LAPC '09), pp. 469472, Loughborough, UK, November 2009.

[12] M. M. Nikolić, A. R. Djordjević, and A. Nehorai, "Microstrip antennas with suppressed radiation in horizontal directions and reduced coupling," IEEE Transactions on Antennas and Propagation, vol. 53, no. 11, pp. 3469-3476, 2005.

[13] K. Parthasarathy, Mutual coupling in patch antenna arrays, M.S. thesis, University of Cincinnati, 2006.

[14] N. Yousefzadeh and C. Ghobadi, "Decreasing of mutual coupling in array antennas by using fractal elements," in Proceedings of the Progress in Electromagnetics Research Symposium, Beijing, China, 2007.

[15] X. Delestre, "Patch-Type Microwave Antenna," United States patent no. 5270722, 1993.

[16] FEKO 5.4, Copyright 2005-2008, EM Software \& Systems-S.A. (Pty) Ltd.
[17] A. Farahbakhsh, S. Tavakoli, and A. Seifolhosseini, "Enhancement of genetic algorithm and ant colony optimization techniques using fuzzy systems," in Proceedings of the IEEE International Advance Computing Conference (IACC '09), pp. 336-339, Patiala, India, March 2009.

[18] MATLAB 7.1, Copyright 1984-2005, The MathWorks Inc. 

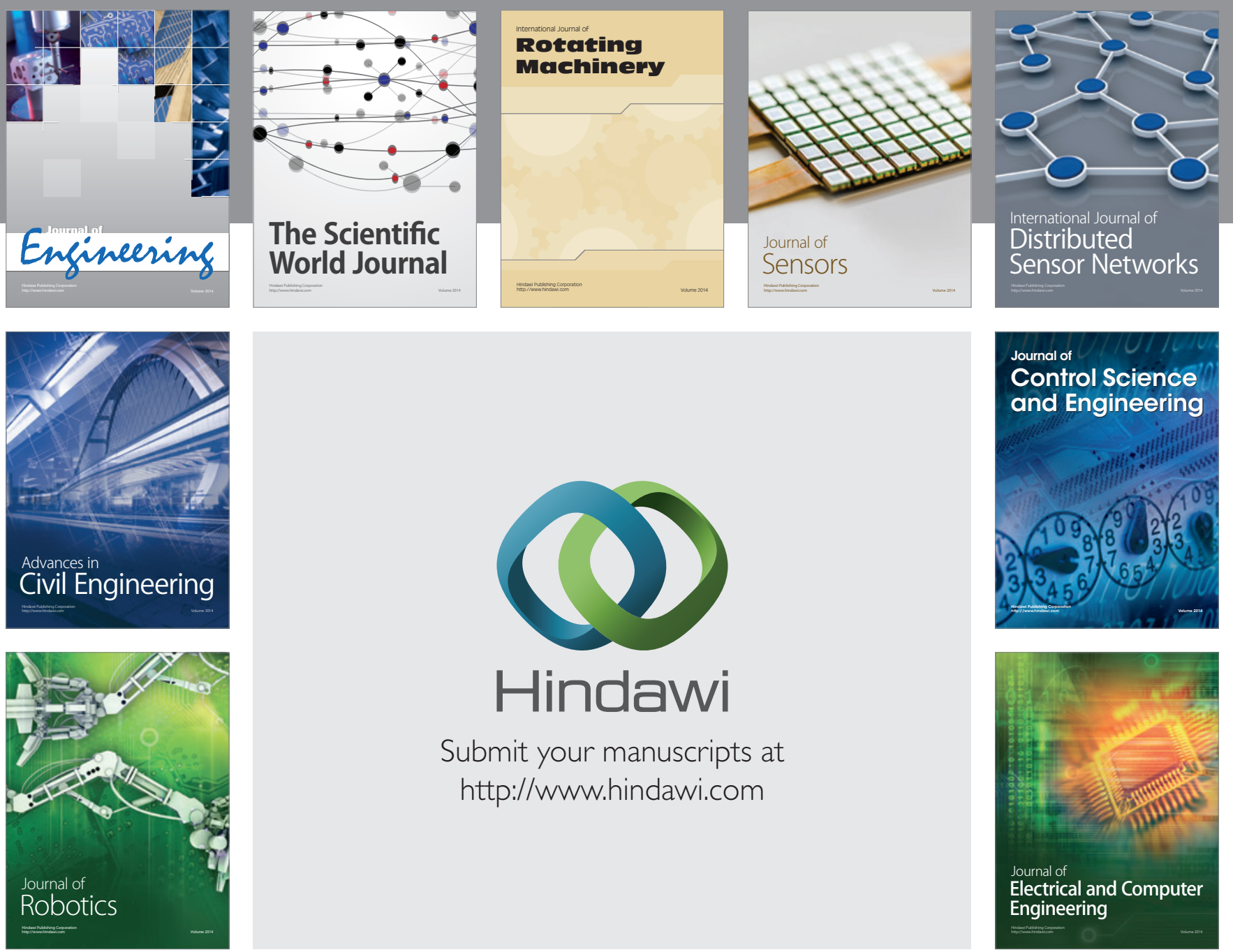

Submit your manuscripts at

http://www.hindawi.com
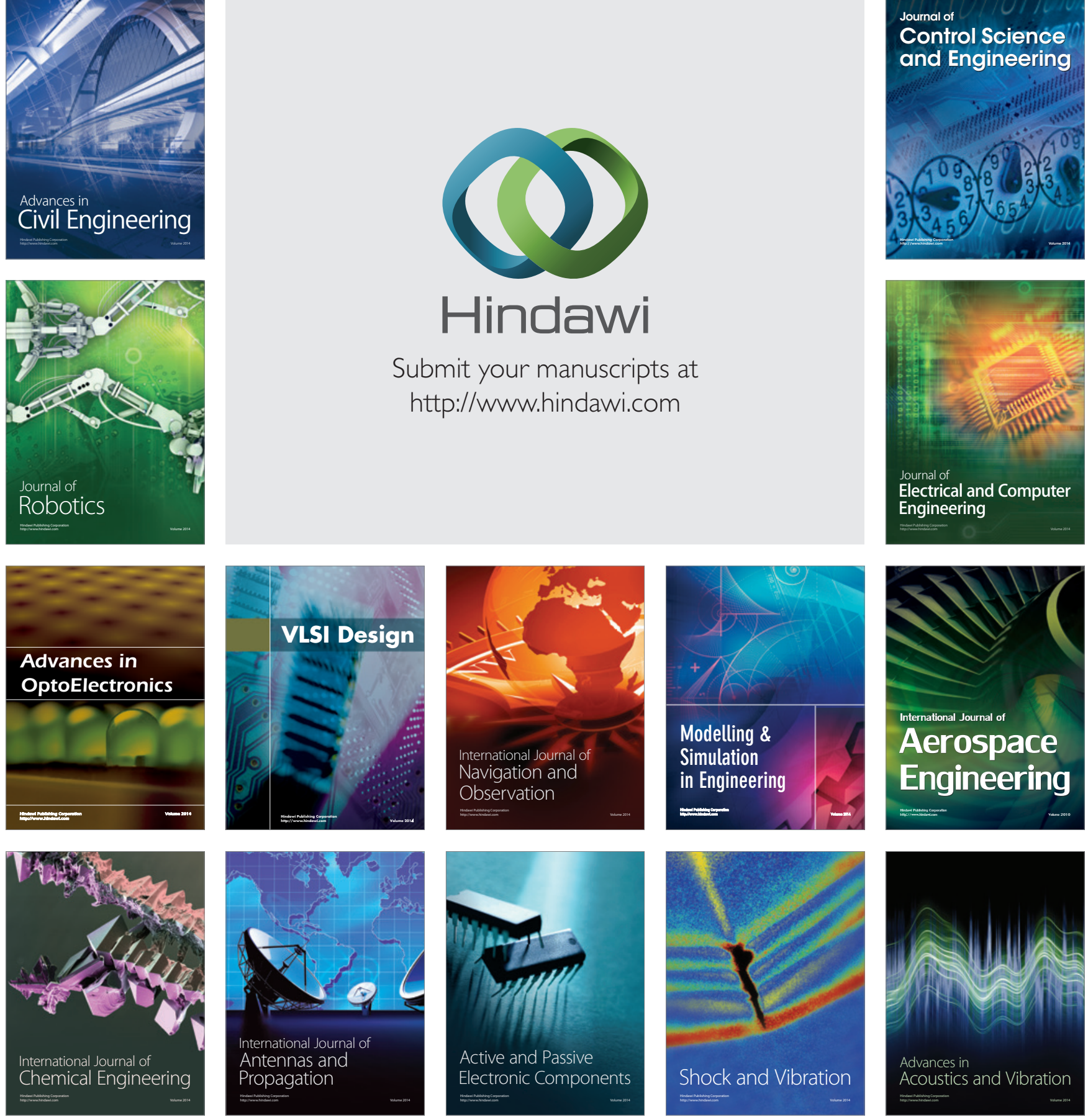